\title{
Synthetic Strategies towards Silica/Poly (Acrylamide-Co-Acrylic Acid) Composites
}

\author{
Nandkishor B. Shirsath ${ }^{1}$, Vikas V. Gite ${ }^{1}$ and Jyotsna S. Meshram ${ }^{1,2^{*}}$ \\ ${ }^{1}$ School of Chemical Sciences, North Maharashtra University, Jalgaon-425 001, India \\ ${ }^{2}$ Department of Chemistry, Rashtrasant Tukadoji Maharaj Nagpur University, Nagpur 440033 , India \\ Email: drjsmeshram@gmail.com
}

\begin{abstract}
Herein, we are reporting increased thermal properties and self-sustaining ability of polymer compositions with silica. The composite of poly (acrylamide-co-acrylic acid) [P(AM-co-AA)] with silica created intermolecular interactions. The formation of a composite has confirmed by FTIR spectroscopy, DSC, TGA, and FE-SEM analysis. The silica particles were homogeneously distributed in the $\mathrm{P}(\mathrm{AM}-\mathrm{co}-\mathrm{AA})$. The incorporation of silica particles gives rise to the enhancement of thermal stability due to the strong interactions between silica and poly (acrylamide-co-acrylic acid) polymer.
\end{abstract}

\section{Graphical Abstract}

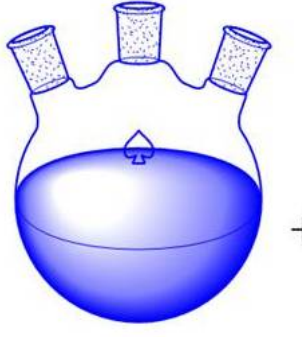

P(AM-co-AA)

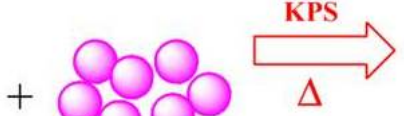

Silica particle

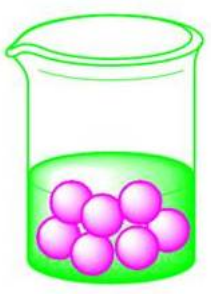

P(AM-co-AA)/Silica composite

Keywords: Poly(acrylamide-co-acrylic acid), silica particles, composite, thermal stability

\section{Introduction}

Polymer composites have been widely studied over a long period of time and over the past few decades, organic polymer-inorganic oxide filler composites have replaced a lot of the conventional polymers in application fields. They are generally organic polymer composites filled with inorganic fillers. Their properties combine the advantages of the inorganic filler material (i. e., rigidity, thermal stability) and of the organic polymer (i.e., flexibility, ductility, process ability) [1]. In addition to such functionalization, composition can successfully reinforce materials; a characteristic example is natural rubbers reinforced by carbon black and silica for practical utilizing as tire materials.

Although the composites strategy is useful for the design of relatively hard functional materials, it is not simple to recognize soft composite materials because of the strong interactions at the interface that decrease the polymer chain mobility [2]. A successful way to improve mechanical properties of a polymer is to create their composites or blend with other polymers that have better mechanical properties for the intended applications [3]. Schmidt et al. synthesised conductive composites of polymer using the biologically active polysaccharide hyaluronic acid (HA) as the dopant in order to create biomaterials for tissue engineering and wound-healing applications [4].

Among inorganic oxide fillers, silica particles have received much attention due to their well-defined ordered structure, high surface area, cost-effective production, and the ease of surface modification [5]. In the polymer composition with silica particles, this can improve thermal properties and self-sustaining 
ability under working environmental conditions. The modification of silica particles leads to better hydrophobic interactions with the polymer and unusual unique properties when compared with unmodified hydrophilic fillers [6, 7]. Porous silica materials with the large specific surface area, high pore volume and tunable pore size are of great interest for academia and industry due to their applications in adsorption, catalysis [8, 9], separation processes [10], drug, delivery systems [11, 12] and gas storage [13, 14.] The possibility of using polymer-silica composites to tailor the textural properties of silica could potentially be of considerable value for new silica applications within the above mentioned fields of interest [15]. The performance of silica materials in many applications requires controlling their morphology and the pore structure. The properties of the composite material may be adjusted by varying the type of inorganic filler, filler size, filler content and blending methods [16]. In addition, the compatibility between the filler surface and the polymer matrix is also an important factor [17].

A three-dimensional cross linked system is formed from a hydrophilic polymer, referred to as a hydrogels, which swells and absorbs water causing the network to swell in solution [18]. Polymeric hydrogels are of great interest for biomaterials applications because of their biocompatibility [19]. These are amongst most attractive classes of "soft matters" with several established and many more possible applications. On the other hand, swelling is limited to rubber like behaviour due to presence of crosslink or strong physical interactions between polymeric chains [20].

The motivation of the current research was to use the silica to prepare silica/P(AM-co-AA) composite by free radical polymerization. This manuscript focuses on more recent trend in the development of silica/polymer composites: materials, synthesis and characterizations of polymer/silica composites.

\section{$2 \quad$ Experimental}

\subsection{Chemicals and Instrumentations}

Acrylamide, tetraethoxysilane (TEOS), ammonia, and ethanol were obtained from Spetrochem Pvt. Ltd., Mumbai, India. Acrylic acid and potassium persulphate (KPS) were purchased from S.D. Fine Chem. Ltd, Mumbai, India.

The infrared spectra of the sample were recorded on a Shimadzu FTIR-8400 frequency range from 400 to $4000 \mathrm{~cm}^{-1}$ using $\mathrm{KBr}$ flakes.

The morphology of the dried sample was examined using S-4800 (SEM) JEOL JSM 6360 \& JEOL JSM 5400 in voltage range of 0.5 to $30 \mathrm{kV}$ instrument after coating the sample with gold film.

Raw materials and polymer composite were analyzed by Differential Scanning Calorimetry (DSC) on Perkin elmer DSC $400010{ }^{\circ} \mathrm{C} / \mathrm{min}$. in temperature from 0 to $300{ }^{\circ} \mathrm{C}$ in steam of nitrogen atmosphere. Thermal stability was determined by Thermal Gravimetric Analysis (TGA) on Perkin elmer TGA 4000 $10{ }^{\circ} \mathrm{C} / \mathrm{min}$.

\subsection{Preparation of Silica Particles}

Silica particles were prepared by the stober process [21]. In $200 \mathrm{~mL}$ beaker tetraethoxysilance (TEOS) was dissolved in ethanol. In another $200 \mathrm{~mL}$ beaker mixture of ammonia, water and ethanol was prepared in 1:1:1 ratio. In this beaker, solution of TEOS was added slowly with constant stirring the mixture for $24 \mathrm{hrs}$. The obtained white precipitate was seapareted by centrifugation the high speed. The obtained silica particles were dried at room temperature.

\subsection{Preparation of Polymer Composites}

$\mathrm{P}(\mathrm{AM}-\mathrm{co}-\mathrm{AA})$ hydrogels were prepared by free radical polymerization of acrylamide and acrylic acid in water. Acrylamide $(5 \mathrm{~g})$ was dissolved in $20 \mathrm{~mL}$ of double distilled water in a $250 \mathrm{~mL}$ three neck round bottom flask equipped with a stirrer, condenser, and thermometer. Acrylic acid $(2 \mathrm{~mL})$ was added to the reaction mixture and stirred at room temperature for $10 \mathrm{~min}$. Silica particles were added to reaction mixture, which was heated at $64^{\circ} \mathrm{C}$ with stirring for $30 \mathrm{~min}$. Potassium persulphate $(0.2 \mathrm{~g})$ was added as a radical initiator into reaction mass for polymerization at constant stirring. The resulting hydrogel was cooled at room temperature. 


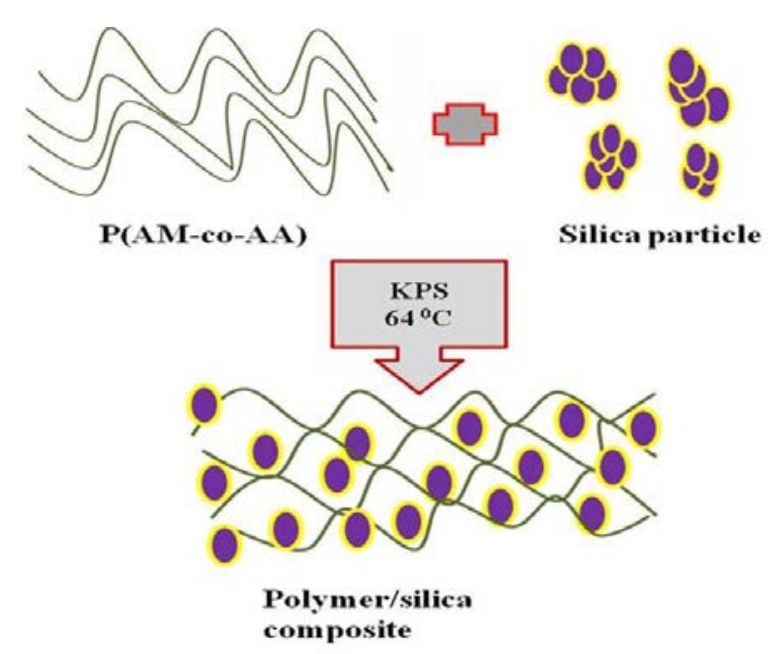

Figure 1. Scheme of $\mathrm{P}(\mathrm{AM}-\mathrm{co}-\mathrm{AA}) /$ silica composite

\section{$3 \quad$ Results and Discussion}

\subsection{FTIR Analysis of Polymer P(AM-co-AA)}

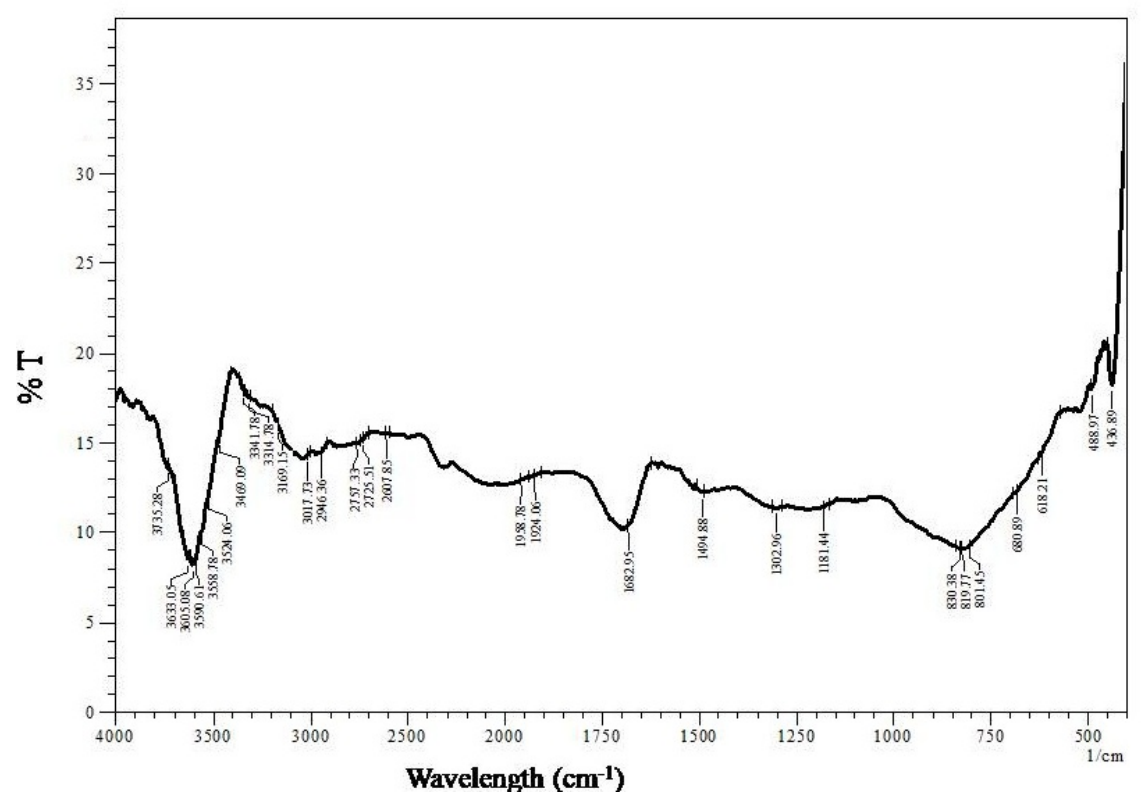

Figure 2. FTIR analysis of $\mathrm{P}(\mathrm{AM}-\mathrm{co}-\mathrm{AA})$ polymer

The infrared spectra of $\mathrm{P}(\mathrm{AM}-\mathrm{co}-\mathrm{AA})$ is given in Fig. 2. The midrange band in the range of 3633-3451 $\mathrm{cm}^{-1}$ are results due to $-\mathrm{NH}_{2}$ from acrylamide, the presence of water in hydrogel and the acidic $-\mathrm{OH}$ of polymer. The $\mathrm{C}-\mathrm{H}$ stretching band is confirmed by presence of band at $2950 \mathrm{~cm}^{-1}$ due to asymmetric stretching vibrations of $-\mathrm{CH}_{2}$ groups in polymer. The amide carbonyl is observed at $1683 \mathrm{~cm}^{-1}$, The band found in between $800-400 \mathrm{~cm}^{-1}$ is due to bending occurring from $\mathrm{NH}$ and $\mathrm{OH}$ groups [22]. 


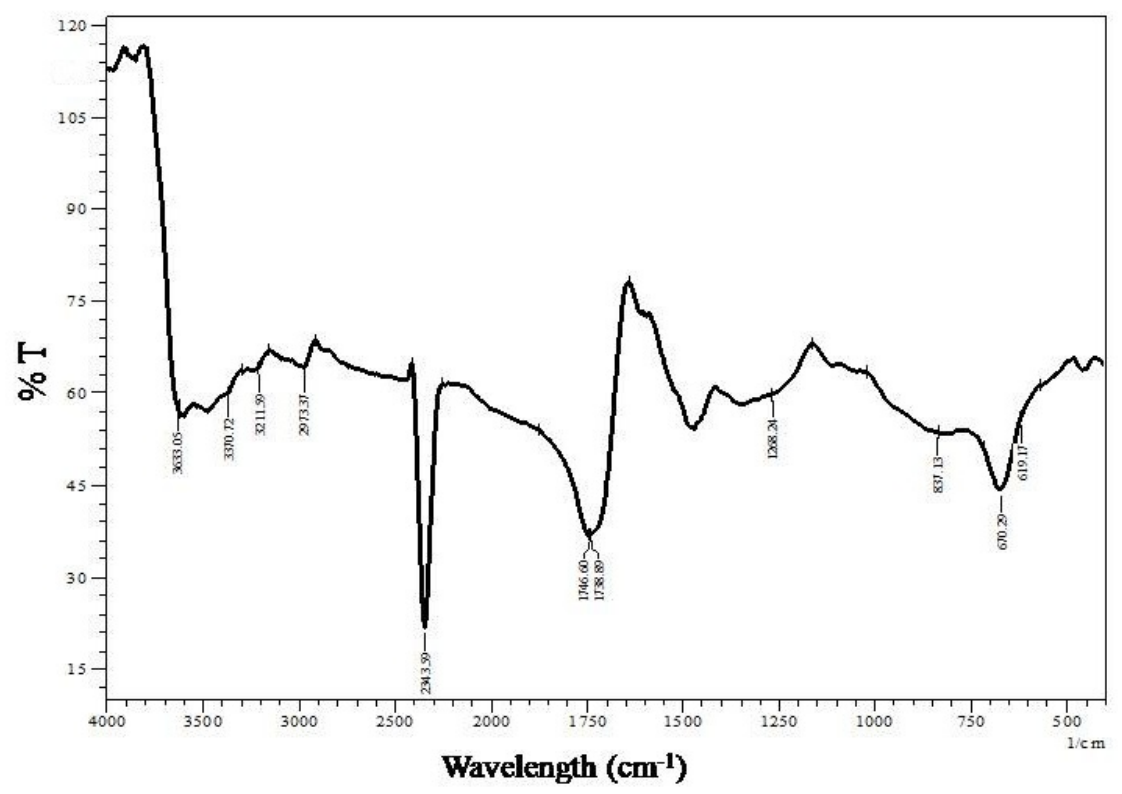

Figure 3. FTIR analysis of $\mathrm{P}(\mathrm{AM}-\mathrm{co}-\mathrm{AA}) /$ silica composites material

The infrared spectra of silica composites are given in Fig. 3. The midrange bands in the range of 3633$3451 \mathrm{~cm}^{-1}$ and decreases up to the $2973 \mathrm{~cm}^{-1}$ are due to intermolecular hydrogen bonding between polymer and silica. The silica particles are confirmed by presence of band at $2343 \mathrm{~cm}^{-1}$. The amide carbonyl is seen at $1746 \mathrm{~cm}^{-1}$. The bands found between $800-600 \mathrm{~cm}^{-1}$ are due to bending occurring from $\mathrm{NH}$ and $\mathrm{OH}$ groups [23].

\subsection{Thermal Stability of Polymeric Compounds}
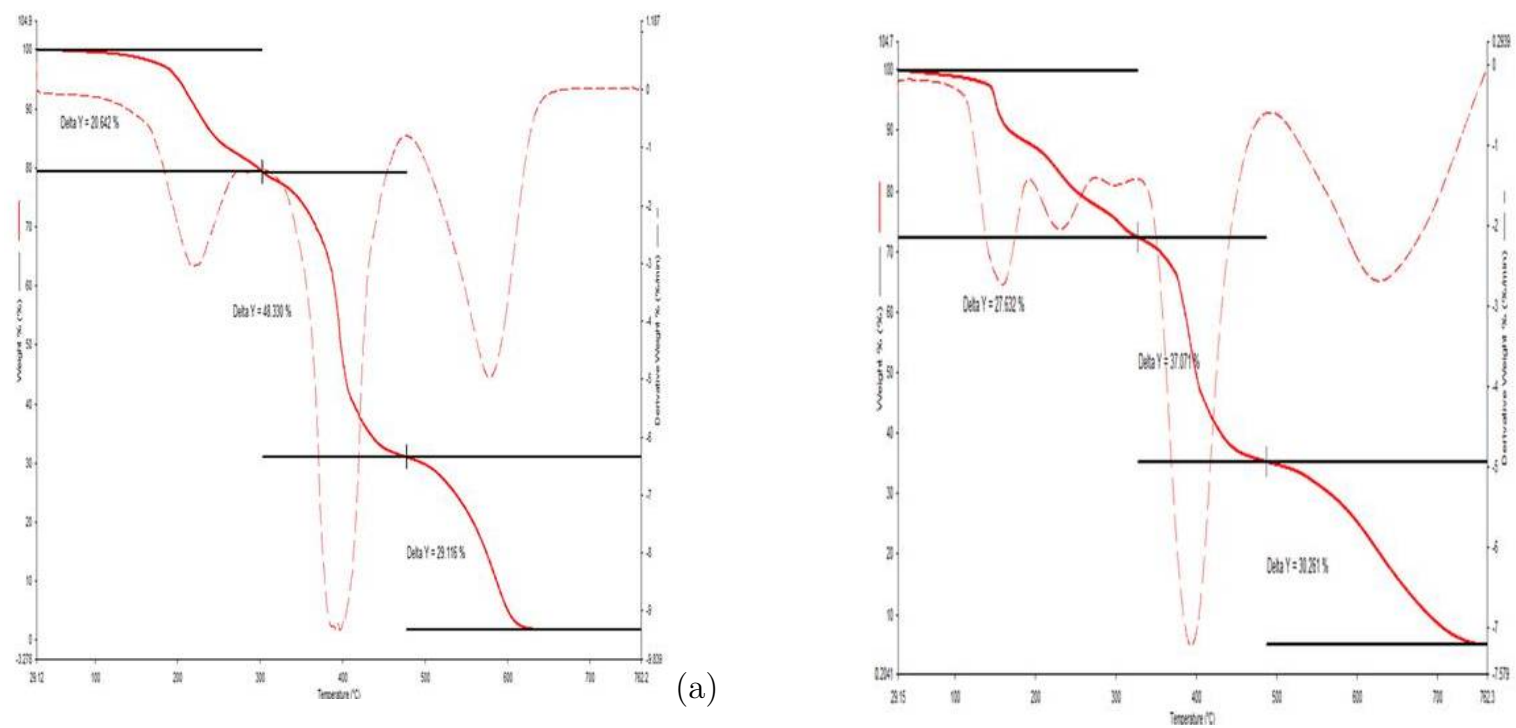

(b)

Figure 4. Thermal gravimetric analysis of (a) $\mathrm{P}(\mathrm{AM}-\mathrm{co}-\mathrm{AA})$ polymer (b) $\mathrm{P}(\mathrm{AM}-\mathrm{co}-\mathrm{AA})$ silica composites material

Thermal stability of $\mathrm{P}(\mathrm{AM}-\mathrm{co}-\mathrm{AA})$ and polymer silica composite were studied by thermogravimetric analysis (TGA) and thermograms are depicted in Fig. 4. The theromogram of (a) P(AM-co-AA) 
exhibited the first step weight loss as a consequence of moisture present. The second step observed in the range of 200 to $350{ }^{\circ} \mathrm{C}$ may be due to the release of ammonia by imidazation or $\mathrm{CH}_{4}$ in the polymer with weight loss $48.3 \%$. The third step mass loss seen in between 350 to $490{ }^{\circ} \mathrm{C}$ is concerned with the carboxylate group present in polymer chain with mass loss $29.11 \%$. The polymer backbone degradation of $\mathrm{P}$ (AM-co-AA) occurred in fourth step which is in the range of 490 to $600{ }^{\circ} \mathrm{C}$ [22]. Figure (b) of polymer silica composites shows three stages of degradation, the first degradation starts from 20 to $320{ }^{\circ} \mathrm{C}$ due to moisture, approximately $27.632 \%$ weight loss. The second degradation occurs between 320 to $490{ }^{\circ} \mathrm{C}$ due to the breaking of polymer chain with $37.071 \%$ weight loss. The final degradation starts from 490 to $720{ }^{\circ} \mathrm{C}$ due to degradation and char of composites and a $30.261 \%$ weight loss. It means the formation of the polymer composite has changes from 620 to $750{ }^{\circ} \mathrm{C}$ relative to the thermal properties of polymer [24].

\subsection{Differential Scanning Calorimetric Analysis}

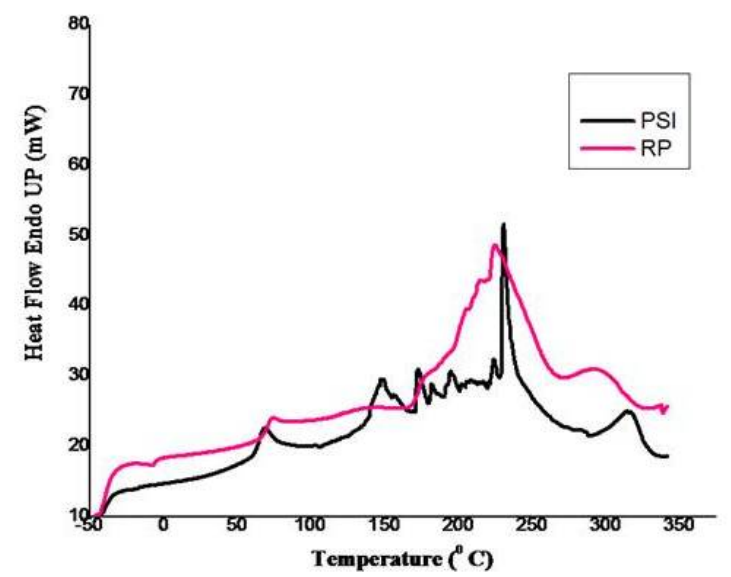

Figure 5. Differential scanning calorimeter of $\mathrm{P}(\mathrm{AM}-\mathrm{co}-\mathrm{AA})[\mathrm{RP}]$ and $\mathrm{P}(\mathrm{AM}-\mathrm{co}-\mathrm{AA}) /$ silica composites (PSI)

The DSC curves for $\mathrm{P}(\mathrm{AM}-\mathrm{co}-\mathrm{AA})$, and $\mathrm{P}(\mathrm{AM}-\mathrm{co}-\mathrm{AA}) /$ silica composite are represented in Fig. 5 under the temperature range of $-50{ }^{\circ} \mathrm{C}$ to $350{ }^{\circ} \mathrm{C}$ in a steam of nitrogen on thermal analysis. From Fig. 5 we concluded that the $\mathrm{P}(\mathrm{AM}-\mathrm{co}-\mathrm{AA})$ shows the glass transition temperature at $75^{\circ} \mathrm{C}$ and the curve of $\mathrm{P}(\mathrm{AM}-\mathrm{co}-\mathrm{AA})$ showing a characteristic endothermic peak at $220{ }^{\circ} \mathrm{C}$ is corresponding to its decomposition while in case of the silica composite the glass transition temperature is at $70{ }^{\circ} \mathrm{C}$ and a broad peak is converted into a sharp endothermic peak at $230{ }^{\circ} \mathrm{C}$. This thermal property is due to intermolecular interactions and supports the formation of polymer composite [25].

\subsection{Surface Characterization}

One of the most important properties that must be considered when studying a hydrogel is its microstructure morphology. Fig. 6(a) shows the silica particles having the spherical shape and is in aggregation form. Figure (b) shows the secondary electron images of $\mathrm{P}(\mathrm{AM}-\mathrm{co}-\mathrm{AA})$ in the watersaturated state. This observation verified that the synthesized polymer structure of $\mathrm{P}(\mathrm{AM}-\mathrm{co}-\mathrm{AA})$ has a porous structure with effective pore sizes in the $150-250 \mathrm{~nm}$ range. It is proposed that these pores are region of water permeation and interactions sites between external stimuli and the hydrophilic groups of the hydrogel. These pores are produced from water evaporation at the time of hydrogel synthesis. The morphology of the composite was studied by scanning electron microscopy in Fig. 6(c). From this image it can be seen that composites have smooth surfaces and the micrographs show the porous nature with a very small amount of silica particle composited in its pore and surface of the sample[26]. 

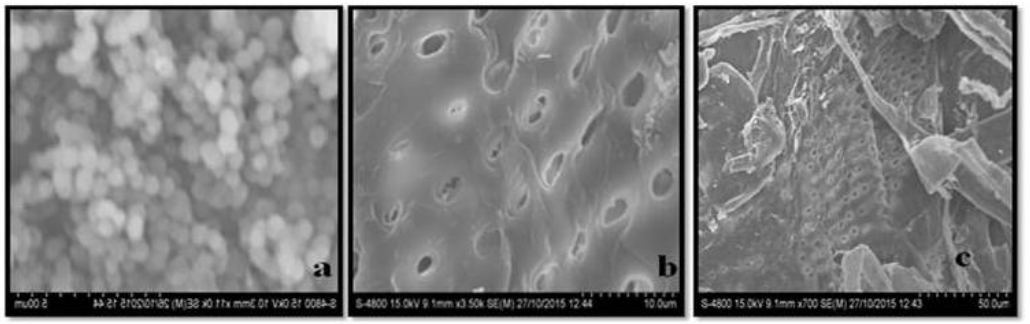

Figure 6. Morphology of a) Silica particles b) P(AM-co-AA) polymer c) P(AM-co-AA) silica composites

\subsection{Elemental Analysis}

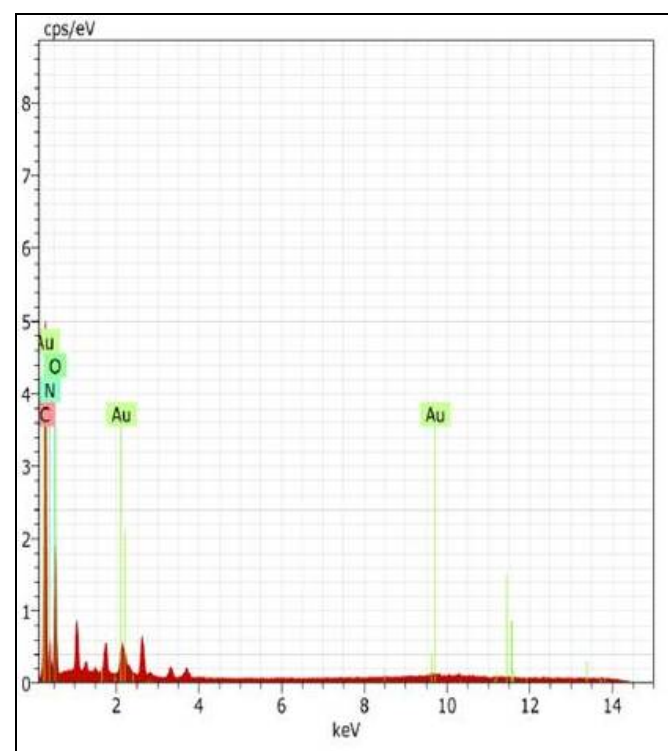

(a)

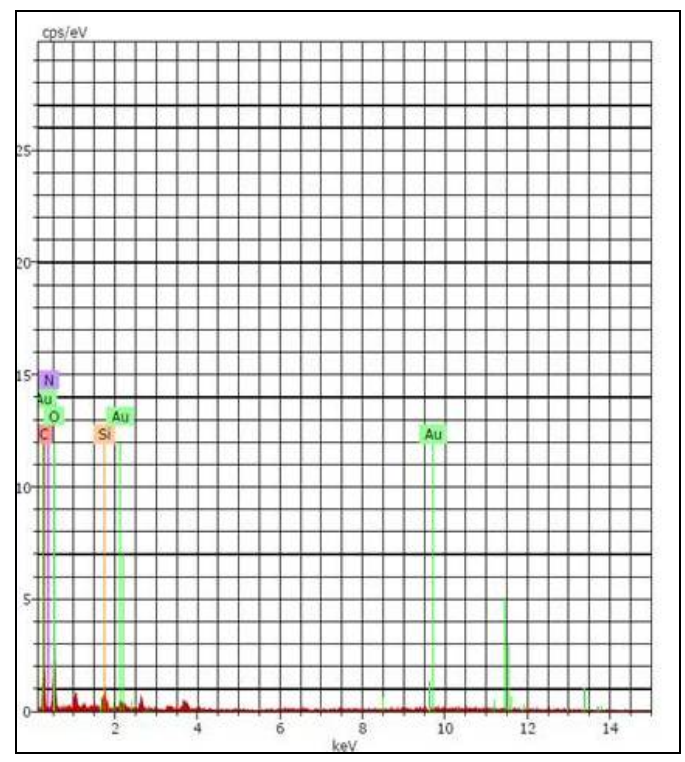

(b)

Figure 7. EDAX analysis of polymeric compounds

From the EDXS analysis in Fig. 7(a), it is clear that the synthesized polymer is non-conducting and contains the carbon, oxygen and nitrogen as the major elements in the composition proving that the synthesized polymer is $\mathrm{P}(\mathrm{AM}-\mathrm{co}-\mathrm{AA})$ while EDXS analysis in Fig. 7(b), indicates carbon, oxygen, nitrogen and silica as the composite material in the synthesized polymer composite $[24,25,26,27]$.

\section{Conclusion}

Herein we demonstrate the synthesis of a composite polymer where the polymer chains are not directly bonded but rather mechanically interlocked to the silica surfaces. The silica particles were homogeneously distributed in the $\mathrm{P}(\mathrm{AM}-\mathrm{co}-\mathrm{AA})$. For obtaining the optimum properties for the composites, requires an excellent homogeneous dispersion of the fillers i.e silica, as the tendency of the silica particles to agglomerate can seriously affect the achievable properties. Therefore, to provide a strong interfacial interaction between the inorganic particles and the polymer matrix, silica fillers must have suitably modified surfaces. 
Acknowledgement

The authors acknowledge the School of Chemical Sciences, North Maharashtra University, Jalgaon and Shri. G. H. Raisoni Doctoral Fellowship for financial support.

\section{References}

1.P. K. Oja, \& A. Nanosiliko, "Nanosilica-reinforced polymer composites" Material in Technologies, 47, pp. 285-293, 2013.

2. K. Kato, D. Matsui, K. Mayumi, K. Ito, "Synthesis, structure, and mechanical properties of silica nanocomposite polyrotaxane gels" Beilstein Journal of Organic Chemistry, 11, pp. 2194-201, 2015.

3. G. Kaur, R. Adhikari, P. Cass, M. Bown, P. Gunatillake, "Electrically conductive polymers and composites for biomedical applications" RSC Advances, 5, pp. 37553-67, 2015.

4. J. H. Collier, J. P. Camp, T. W. Hudson, C. E. Schmidt, "Synthesis and characterization of polypyrrolehyaluronic acid composite biomaterials for tissue engineering applications" Journal of Biomedical Materials Research, 50, pp. 574-84, 2000.

5. R. K. Iler, "The chemistry of silica: solubility, polymerization, colloid and surface properties, and biochemistry" Wiley, 1979.

6. D. W. Lee, B. R. Yoo, "Advanced silica/polymer composites: Materials and applications" Journal of Industrial and Engineering Chemistry" 38, pp. 1-12, 2016.

7. M. S. Lee, N. J. Jo, "Coating of methyltriethoxysilane-modified colloidal silica on polymer substrates for abrasion resistance" Journal of Sol-gel Science and Technology, 24, pp.175-80, 2002.

8. P. Krasucka, J. Goworek, A. Kierys, "Synthesis of the mesostructured polymer-silica composite and silicon dioxide through polymer swelling in silica precursor Adsorption" 22, pp. 663-71, 2016.

9. V. K. Gupta, I. Tyagi, S. Agarwal, H. Sadegh, R. Shahryari-ghoshekandi, M. Yari, O. Yousefi-nejat, "Experimental study of surfaces of hydrogel polymers HEMA, HEMA-EEMA-MA, and PVA as adsorbent for removal of azo dyes from liquid phase" Journal of Molecular Liquids, 206, pp. 129-36, 2015.

10. H. Sepehrian, R. Yavari, M. Ghannadi Maragheh, S. Waqif Husain, "Sorption of radionuclides on mesoporous Sn (IV) silicate: a new sorbent" Radiochimica Acta, 96, pp. 105-9, 2008.

11.H. W. Kim, H. W. Yoon, S. M. Yoon, B. M. Yoo, B. K. Ahn, Y. H. Cho, H. J. Shin, H. Yang, U. Paik, S. Kwon, J. Y. Choi, "Selective gas transport through few-layered graphene and graphene oxide membranes" Science, 342, pp. 91-5, 2013.

12. E. Ruiz-Hernández, A. Lopez-Noriega, D. Arcos, I. Izquierdo-Barba, O. Terasaki, M. Vallet-Regí, "Aerosolassisted synthesis of magnetic mesoporous silica spheres for drug targeting" Chemistry of Materials, 19, pp. 345563, 2007.

13. V. C. Menon, S. Komarneni, "Porous adsorbents for vehicular natural gas storage: a review" Journal of Porous Materials, 5, pp. 43-58, 1998.

14. T. C. Chang, E. A. Wentzel, O. A. Kent, K. Ramachandran, M. Mullendore, K. H. Lee, G. Feldmann, M. Yamakuchi, M. Ferlito, C. J. Lowenstein, D. E. Arking, "Transactivation of miR-34a by p53 broadly influences gene expression and promotes apoptosis" Molecular Cell, 26, pp. 745-52, 2007.

15. A. Kierys, M. Rawski, J. Goworek, "Polymer-silica composite as a carrier of an active pharmaceutical ingredient" Microporous and Mesoporous Materials, 193, pp. 40-6, 2014.

16. M. J. Aryee, A. E. Jaffe, H. Corrada-Bravo, C. Ladd-Acosta, A. P. Feinberg, K. D. Hansen, R. A. Irizarry, "Minfi: a flexible and comprehensive Bioconductor package for the analysis of Infinium DNA methylation microarrays" Bioinformatics, 30, pp. 1363-9, 2014.

17. A. Kierys, "Synthesis of Aspirin-loaded Polymer-Silica Composites and their Release Characteristics" ACS Applied Materials \& Interfaces, 6, pp. 14369-76, 2014.

18. Li, Jun, "Self-assembled supramolecular hydrogels based on polymer-cyclodextrin inclusion complexes for drug delivery" NPG Asia Materials, 2, pp. 112-118, 2010.

19. D. Valle, E. M. Martin, "Cyclodextrins and their uses: a review" Process Biochemistry, 39, pp. 1033-1046, 2004. 
20. Yang, Qian et al. "Composites of functional polymeric hydrogels and porous membranes" Journal of Materials Chemistry, 21, pp. 2783-2811, 2011.

21. Rahman, I. A., Padavettan, V. "Synthesis of silica nanoparticles by sol-gel: size-dependent properties, surface modification, and applications in silica-polymer nanocomposites - a review" Journal of Nanomaterials, 2012, pp. $1-8,2012$.

22. Li Jing et al. "Inclusion complexes of fluconazole with $\boldsymbol{\beta}$-cyclodextrin and 2-hydroxypropyl- $\boldsymbol{\beta}$-cyclodextrin in aqueous solution: preparation, characterization and a structural insight" Journal of Inclusion Phenomena and Macrocyclic Chemistry, 3, pp. 209-217, 2016.

23. A. Beganskienė, V. Sirutkaitis, M. Kurtinaitiené, R. Juškènas, A. Kareiva, "FTIR, TEM and NMR investigations of Stöber silica nanoparticles" Mater Sci, 10, pp. 287-90, 2004.

24. W. J. Rieter, J. S. Kim, K. M. Taylor, H. An, W. Lin, T. Tarrant, W. Lin, "Hybrid silica nanoparticles for multimodal imaging" Angewandte Chemie International Edition, 46, pp. 3680-2, 2007.

25. R. Y. Hong, H. P. Fu, Y. J. Zhang, L. Liu, J. Wang, H. Z. Li, Y. Zheng, "Surface-modified silica nanoparticles for reinforcement of PMMA" Journal of Applied Polymer Science, 105, pp. 2176-84, 2007.

26. M. Yu, G. Gu, W. D. Meng, F. L. Qing, "Superhydrophobic cotton fabric coating based on a complex layer of silica nanoparticles and perfluorooctylated quaternary ammonium silane coupling agent" Applied Surface Science, 253, pp. 3669-73, 2007.

27. P. P. Kumavat, D. S. Dalal, "Fabrication of Organic Solar Cells based on Photosensitive Small Molecules and Study of Electron Acceptor Layer Effect on Efficiency" Modern Organic Chemistry Research, 1, pp. 35-42, 2016. 